\title{
Predicting the 2019 M7 Strong Earthquake in California
}

\author{
Guangmeng Guo, Yongtao Jiang \\ Nanyang Normal University, Nanyang, China \\ Email: guogm@igsnrr.ac.cn
}

How to cite this paper: Guo, G.M. and Jiang, Y.T. (2021) Predicting the 2019 M7 Strong Earthquake in California. International Journal of Geosciences, 12, 941-948. https://doi.org/10.4236/ijg.2021.1210048

Received: August 19, 2021

Accepted: October 9, 2021

Published: October 12, 2021

Copyright $\odot 2021$ by author(s) and Scientific Research Publishing Inc. This work is licensed under the Creative Commons Attribution International License (CC BY 4.0).

http://creativecommons.org/licenses/by/4.0/

\begin{abstract}
The U.S. Geological Survey has estimated a 99\% chance of a magnitude 6.7 earthquake in California in the next 30 years from 2008. In this paper, Fourier transform, mode analysis and commensurability analysis are used to study the earthquake cycle in California and predict the future strong earthquake. The analysis shows that the strong earthquake in California is most likely to occur in 2019, and the prediction was sent to the relevant institutions of United States in 2018. In July 2019 an M7.1 earthquake occurred in California, which proved our prediction to be correct.
\end{abstract}

\section{Keywords}

California, Earthquake Prediction, The Fourier Transform, Commensurability

\section{Introduction}

California is the state with the most severe earthquake disaster in the United States. Therefore, earthquake prediction in this area is particularly important. The U.S. Geological Survey (USGS) has made two famous earthquake predictions in California. One is for the Parkfield area in southern California. They found that the earthquake in this area has a cycle of about 22 years. The last earthquake occurred in 1966, so they predicted the next earthquake may occur around 1988 (1983-1993) with probability of 95\% [1] [2]. The actual earthquake occurred in 2004, 11 years later than expected and this proved that the earthquake prediction was a failure [3]. The second time is the long-term probability prediction of the California earthquake. In 2008, USGS reported that the probability of an M6.7 earthquake in California in the next 30 years is $99 \%$ (https://www.sciencedaily.com/releases/2008/04/080414203459.htm). Because the forecast period is as long as 30 years, the actual disaster mitigation significance 
of this forecast is not great. Here we propose a new method to predict which year will have the greatest probability of earthquake occurrence during the period, and reduce the time from 30 years to 1 year, which is helpful for disaster reduction and prevention.

\section{Regional Seismic Data}

The historical seismic data of the California area was downloaded from the website of the US Geological Survey

(https://earthquake.usgs.gov/earthquakes/search/). A total of 14 strong earthquakes of M6.7 or above occurred from 1900 to 2018 (see Table 1). The distribution is shown in Figure 1.

\section{Earthquake Prediction Methods and Result Analysis}

\subsection{Forecast the Year of Earthquake}

\subsubsection{Fourier Transform}

Fourier transform can get the main period of a time series [4]. Wang Xiang et al. (2010) used the Fourier transform method to compare the quasi-periodicity of the time-magnitude series of $30 \mathrm{M}_{\mathrm{S}} \geq 5.0$ earthquakes which occurred in the border area of Shanxi, Hebei and Mongolia from 1494 to 2009 [5]. The results show that the earthquake sequence in the area has a cycle of 11 years and 8.6 years. In this paper, Fourier transform is performed on the sequence of strong earthquakes in the California area, and the main earthquake periods are 5 and 9 years (Figure 2(a), Figure 2(b)).

Taking the five recent earthquakes in California in 1989, 1992, 1994, 1999 and

Table 1. Sequence of strong earthquakes in California, USA from 1900 to 2018.

\begin{tabular}{|c|c|c|c|c|c|c|}
\hline No. & Year & Month & date & Lat & Lon & $\mathbf{M}$ \\
\hline 1 & 1906 & 4 & 18 & 37.7 & -122.5 & 7.9 \\
\hline 2 & 1915 & 11 & 21 & 32 & -115 & 7 \\
\hline 3 & 1918 & 4 & 21 & 33.7 & -117 & 6.8 \\
\hline 4 & 1925 & 6 & 29 & 34.3 & -119.8 & 6.8 \\
\hline 5 & 1927 & 11 & 4 & 34.8 & -120.7 & 6.9 \\
\hline 6 & 1940 & 5 & 19 & 32.8 & -115.4 & 6.9 \\
\hline 7 & 1952 & 7 & 21 & 34.9 & -118.9 & 7.5 \\
\hline 8 & 1956 & 2 & 9 & 31.8 & -116.2 & 6.8 \\
\hline 9 & 1983 & 5 & 2 & 36.2 & -120.3 & 6.7 \\
\hline 10 & 1989 & 10 & 18 & 37 & -121.8 & 6.9 \\
\hline 11 & 1992 & 6 & 28 & 34.2 & -116.4 & 7.3 \\
\hline 12 & 1994 & 1 & 17 & 34.2 & -118.5 & 6.7 \\
\hline 13 & 1999 & 10 & 16 & 34.6 & -116.3 & 7.1 \\
\hline 14 & 2010 & 4 & 4 & 32.2 & -115.3 & 7.2 \\
\hline
\end{tabular}




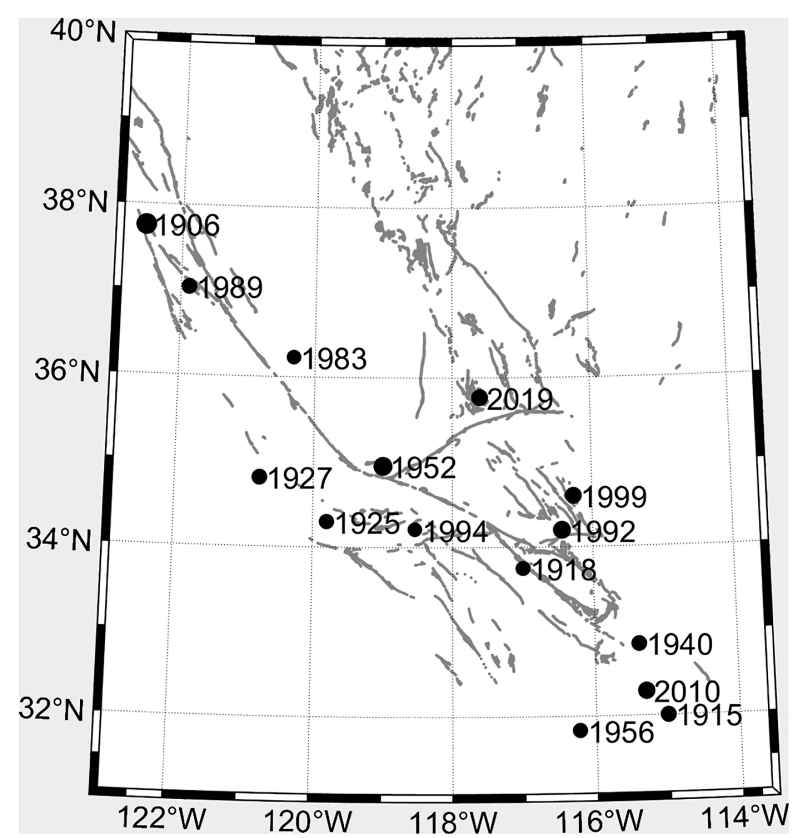

Figure 1. Distribution of strong earthquakes in California, USA from 1900 to 2018 (the gray solid line is the regional faults).
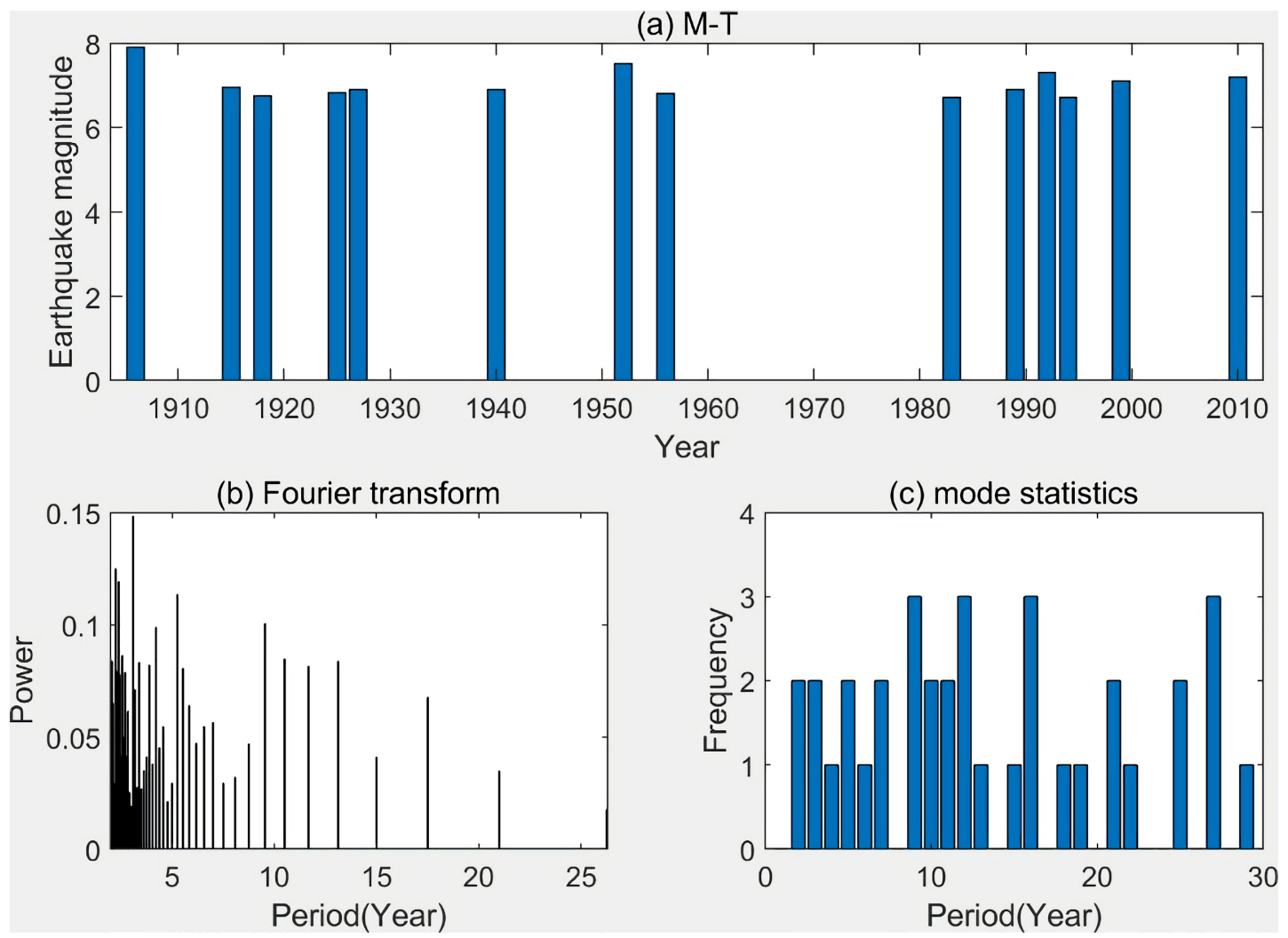

Figure 2. (a) Strong earthquake sequence in California, USA, and (b) its Fourier transform and (c) mode statistics.

2010 as the starting point, the calculations are based on 5-year and 9-year cycles respectively. The results are as follows: 
1) Calculation based on 5 -year cycle

19891994199920042009201420192024

19921997200220072012201720222027

1994199920042009201420192024

199920042009201420192024

20102015202020252030

2) Calculation based on 9 -year cycle

198919982007201620252034

199220012010201920282037

19942003201220212030

1999200820172026

2010201920282029

The statistics result shows that 2019 is the most frequent year which appears 5 times, while for other years (2015-2035) they appear only 1-3 times (Figure 3).

\subsubsection{Mode Analysis}

The mode is the value that appears most frequently in a data sequence, and reflects the value that has an obvious central tendency point on the statistical distribution of the data. In this paper, we subtracted the data of the earthquake sequence in California to obtain the data sequence of the interval between earthquakes. The frequency statistical analysis was performed, and the earthquake period was extracted. The result is shown in Figure 2(c). It can be seen that in the sequence of strong earthquakes in California, the most frequent cycles are 9, 12, 16 , and 27 years, and here we used these cycles to forecast.

1) 9 years cycle

198919982007201620252034

199220012010201920282037

19942003201220212030

1999200820172026

2010201920282029

2) 12 years cycle

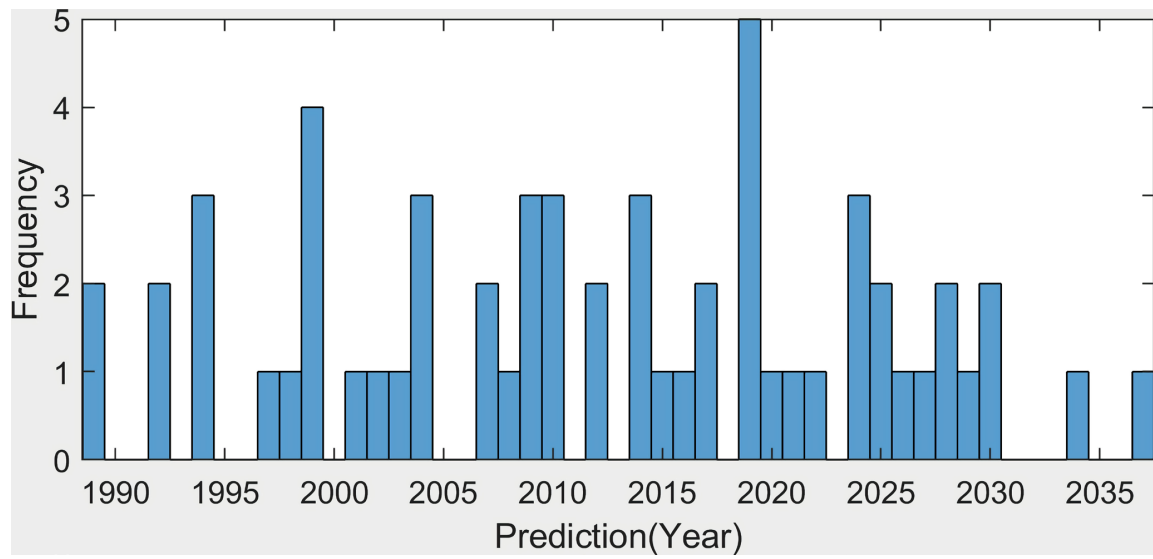

Figure 3. Earthquake prediction based on Fourier transform. 
1989200120132025

1992200420162028

1994200620182030

199920112023

20102022

3) 16 years cycle

198920052021

199220082024

19942020

19992015

20102026

4) 27 years cycle

19892016

19922019

19942021

19992026

20102037

According to statistical analysis, after M7 earthquake in southern California in 2010, the most frequent years are 2016, 2019, 2021, 2026 and 2028. Because there is no strong earthquake in 2016, so 2019 is the next most likely years (Figure 4).

\subsubsection{Commensability Analysis}

The commensurability of the earthquake sequence is an expansion of the earthquake periodicity, namely the mixed law that appears after periods of different lengths are superimposed on each other, which reflects the objective periodic order of strong earthquakes in the region, and it is valuable for earthquake prediction [6]. With the commensurability method, in 2006 Long Xiaoxia predicted that the next possible $M_{s} \geq 6.7$ earthquake in the Sichuan-Yunnan area was 2008, and the result was an M8.0 earthquake occurred in Wenchuan County, Sichuan Province on May 12, 2008 [7]. In 2008 Yan studied the trend of strong earthquakes in western China based on commensurability, and predicted that the

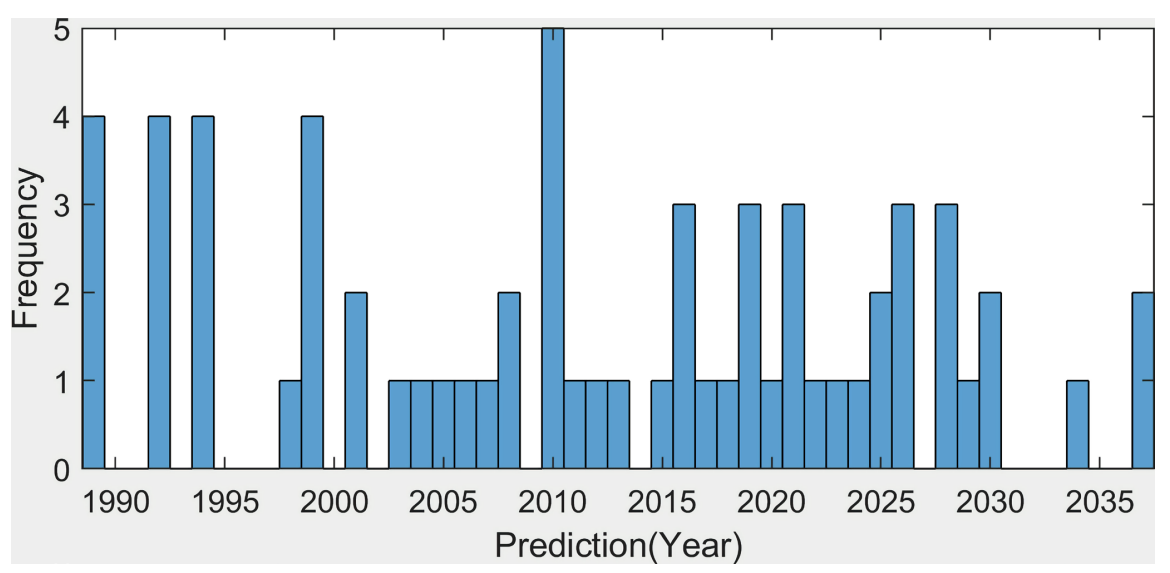

Figure 4. Earthquake prediction based on modal analysis. 
next possible $M_{s} \geq 7.2$ earthquake in the Sichuan-Yunnan seismic zone would be 2010. As a result, a M7.1 earthquake occurred in Yushu, Qinghai on April 14, 2010 [8]. Here we use the quaternary commensurability method to predict the sequence of strong earthquakes in California. The formula is $X_{a}+X_{b}=X_{c}+X_{d}$ where $X_{a}, X_{b}, X_{\circ}$ and $X_{d}$ are the earthquake occurrence years. The results show that 2019 is the year with the highest probability of earthquakes from 2015 to 2022 (see Figure 5).

\subsection{Estimation of the Earthquake Month}

We plot the month of 14 California earthquakes on the wind rose map. The most frequent are 5 times for April and October, 4 times for May and November, and 2 times for January and July which show obvious clustering. The above earthquake months are opposite each other, separated by half year, and appear as a straight line on the earth's orbit, which conforms to the 180-day periodic law we discovered [9]. In terms of frequency, most earthquakes occurred from April to July, and the fact is the strong earthquakes in 2019 occurred in July. At the same time, July, April, and October showed a vertical distribution. Therefore, based on the month of the historical earthquake, it is possible to estimate the month of the earthquake (Figure 6).

\subsection{Estimation of the Epicenter Location}

Earthquake migration is a phenomenon that earthquake shows a directional migration within an earthquake zone. Studies have shown that the earthquake has an orderly migration phenomenon on the Qilianshan fault zone, Xianshuihe fault zone and north-south seismic zone in many country [10]. In Figure 7, we list the migration process of earthquakes in California in terms of longitude and latitude. For latitude, there have been two earthquakes in California in history that occurred near the latitude about $32^{\circ}$, and then went northward to $33.7^{\circ}$ and $36.2^{\circ}$. The M7 earthquake in 2010 occurred at N32 , so it is speculated that the next earthquake should be around $\mathrm{N} 34^{\circ}-36^{\circ}$. The actual latitude of the strong earthquake that occurred in July 2019 is $35.7^{\circ}$, which is consistent with the estimation. For longitude, there are 4 earthquakes that the longitude changes from

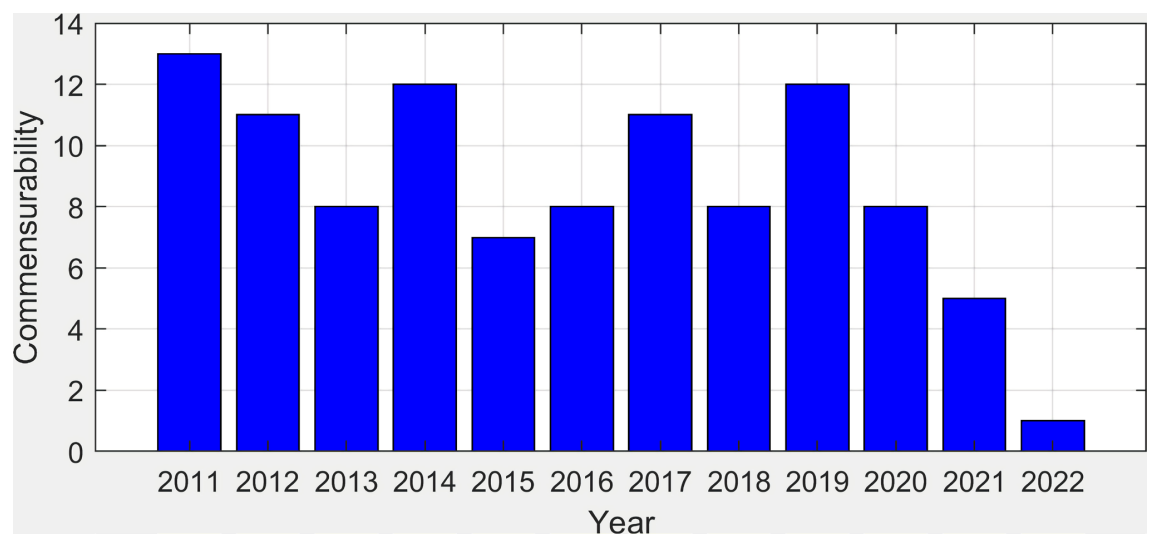

Figure 5. Earthquake prediction based on commensurability. 


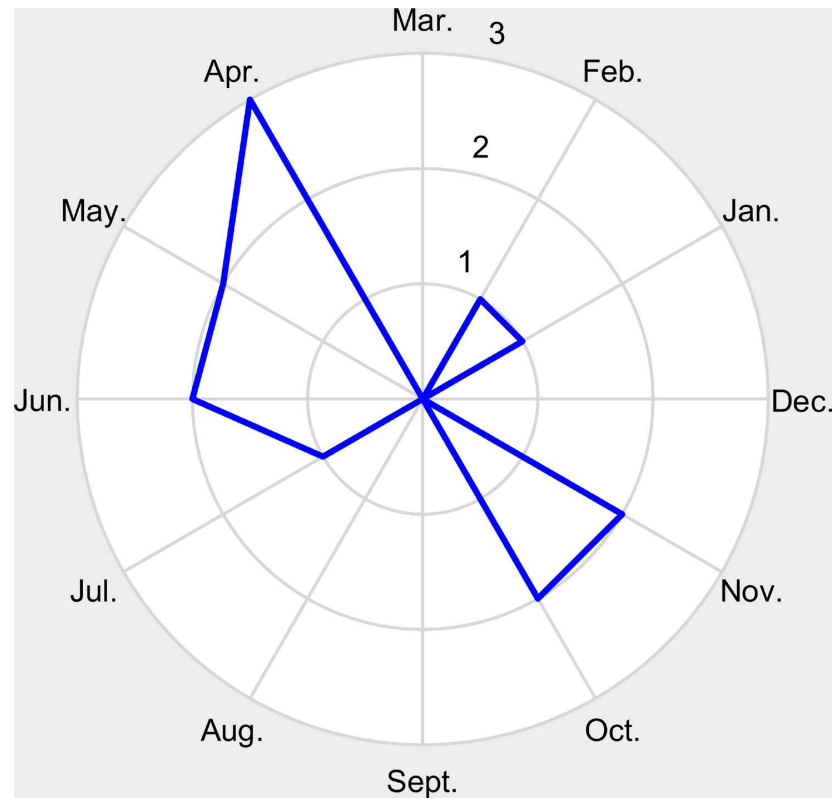

Figure 6. Wind rose map of the month of earthquakes.

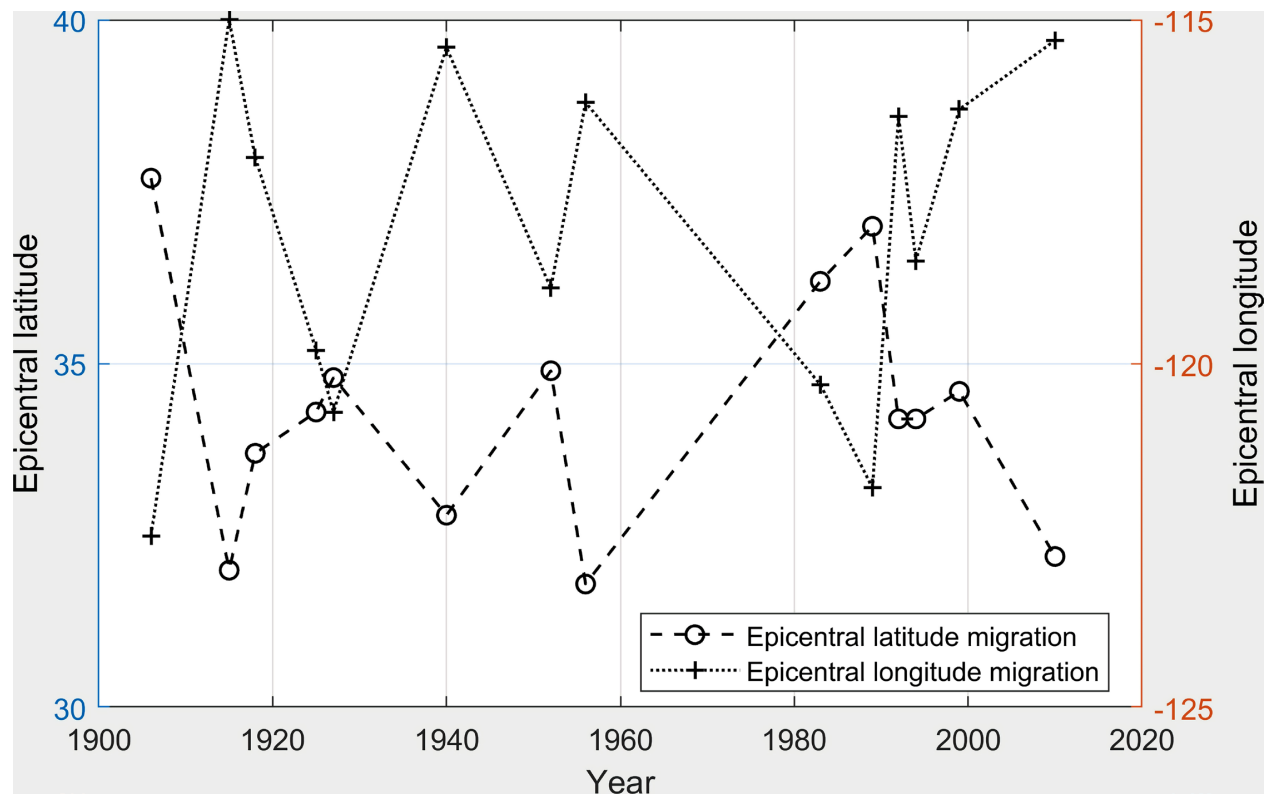

Figure 7. The epicenter shift pattern of the California earthquakes.

$-115^{\circ}$ to $-117^{\circ}$, from $-115.4^{\circ}$ to $-118.9^{\circ}$, from $-116.2^{\circ}$ west to $-120.3^{\circ}$, and from $-116.4^{\circ}$ to $-118.5^{\circ}$, and all the 4 earthquakes moved from east to west. The longitude of the strong earthquake in 2010 is $-115.3^{\circ}$. According to the above rules, it is speculated that the next strong earthquake will also move westward, possibly between $-120^{\circ}$ and $-117^{\circ}$. The actual longitude of the strong earthquake in July 2019 is $-117.6^{\circ}$, which is consistent with the estimation.

\section{Conclusions}

In 2018 we used Fourier transform, mode analysis, and commensurability analy- 
sis and predicted that California is most likely to have a strong earthquake of M6.7 or above in 2019, and the prediction was sent to the White House government, California Office of Disaster Mitigation, U.S. Geological Survey and other related agencies in 2018 and received their receptions. An M7.1 earthquake occurred in California on July 6, 2019. The facts have proved our prediction.

The method of USGS scientists can only give the probability of earthquake occurrence in the next 30 years. Our method can predict the earthquake occurrence period within 1 year, which shortens the time window greatly and is of great significance to disaster reduction and prevention in California. Through the month prediction analysis and the epicenter migration analysis, it is found that the law of California earthquakes is clear, and it is possible to use this law to predict the location and month of future strong earthquakes, which provides the possibility for disaster reduction and prevention.

\section{Conflicts of Interest}

The authors declare no conflicts of interest regarding the publication of this paper.

\section{References}

[1] Bakun, W.H. and Mcevilly, T.V. (1984) Recurrence Models and Parkfield, California, Earthquakes. Journal of Geophysical Research: Solid Earth, 89, 3051-3058. https://doi.org/10.1029/JB089iB05p03051

[2] Bakun, W.H. and Lindh, A.G. (1985) The Parkfield, California, Earthquake Prediction Experiment. Science, 229, 619-624. https://doi.org/10.1126/science.229.4714.619

[3] Bakun, W.H., Aagaard, B., Dost, B., et al. (2005) Implications for Prediction and Hazard Assessment from the 2004 Parkfield Earthquake. Nature, 437, 969-974. https://doi.org/10.1038/nature04067

[4] Jiang, C.J. and Jiang, Y. (2004) Fast Fourier Transform and C Program. University of Science and Technology of China Press, Hefei.

[5] Wang, X., Feng, X.D., Ping, J.J., et al. (2010) Analysis and Study of Seismic Time Series Spectrum in the Border Area of Shanxi, Hebei and Mongolia. Seismic Geomagnetic Observation and Research, 31, 14-19.

[6] Weng, W.B. (1984) Basis of Prediction. Petroleum Industry Press, Beijing.

[7] Long, X.X., Yan, J.P., Sun, H., et al. (2006) Study the Earthquake Tendency in Sichuan-Yunnan Region with Commensurability. Journal of Disaster, 21, 81-84.

[8] Yan, J.P. and Yan, N. (2008) About the Possibility and Verification of Earthquake Prediction System. Journal of Shaanxi Normal University (Philosophy and Social Sciences Edition), 37, 19-23.

[9] Liu, J.J., Zhao, Q.F. and Guo, G.M. (2014) Prediction and Analysis about the Yaan M7.0 Earthquake. Journal of Nanyang Normal University, 13, 29-33.

[10] Ma, Z.J., Li, X.Z. and Jin, J.Y. (1992) The Law, Interpretation and Prediction of Earthquake Migration-Earthquake Migration of Four Seismic Belts in China. Seismology and Geology, 14, 129-139. 